Urban Studies, Vol. 38, No. 2, 287-298, 2001

\title{
The Socio-spatial Construction of (In)accessible Public Toilets
}

\author{
Rob Kitchin and Robin Law
}

[Paper received in final form, August 2000]

\begin{abstract}
Summary. This paper examines the rights of disabled people to access public spaces in Western societies through an analysis of the provision of accessible public toilets in Ireland. Providing a critical analysis around the themes of social justice and citizenship, the investigation is based on an examination of present-day planning legislation, interviews conducted with 35 disabled people-19 in the Republic of Ireland and 16 in Northern Ireland-and a case study of one particular town, Newbridge, County Kildare, Ireland. These data reveal that in Ireland and the UK, planning legislation is weak and often not enforced. Accessible public toilets are few and far between; those that do exist are often poorly designed; and, this lack of provision severely delimits the daily spatial behaviour of disabled people. This lack of provision, it is argued, is expressive of a wider set of ableist power geometries and signifies that disabled people do not, as yet, have the same civil rights as non-disabled people.
\end{abstract}

\section{Introduction}

Geographers and others have recently started to document how space is socially produced in ways that deny disabled people the same levels of access as non-disabled people. Adopting a largely critical position, they have sought to expose both the ways in which disabled people are excluded from full participation in society through the social production of space; and, the spatial manifestations of unequal social relations (see Kitchin, 1998). It is clear that, despite varying approaches to the study of this subject, researchers agree that disabled people live in 'transformed spaces' (Golledge, 1993) and occupy a 'negative reality' (Finkelstein, 1993). ${ }^{1}$ That is, there are distinct geographies of disability that differ in largely negative terms from the geographies experienced by non-disabled people.

In this paper, we use an analysis of interviews with 35 disabled people in Ireland and a case study of one town, Newbridge, to describe one such differing geography - that of the provision of accessible public toilets. Focusing on access to toilets might at first seem myopic. However, we would contend that the public toilet is still very much at the heart of contemporary struggles over space and provides a useful illustration of a larger point: how landscapes are constructed through particular power geometries and shaped by notions of citizenship and social justice. Indeed, the provision and siting of toilets is highly illustrative of the socio- 
spatial processes that regulate and exclude disabled people from everyday spatial arenas, and reveals the extent to which many public spaces represent 'landscapes of exclusion'.

\section{Public Toilets, Disability, Citizenship and Social Justice}

In recent years, the disability movement has been at the forefront of the struggle to redefine citizenship and social justice with reference to embodiment; in other words, to ensure that civil rights are not simply abstract, but can be exercised by human beings with all kinds of bodies. Activists and scholars have repeatedly argued that full participation in civic affairs - an essential element of social justice-depends on the material conditions which shape people's ability to participate (Gleeson, 1999). For disabled people, the provision of public services and the design of the built environment can be a crucial determinant of participation. Although the issues of appropriate design of services and sites are generally recognised, the focus of attention has tended to be on building design and public transport, with relatively little work that specifically addresses public toilets. Yet we would argue that the topic deserves closer attention, for a consideration of the provision of public toilets raises interesting questions concerning citizenship, loosely defined here as the civil and welfare rights that a state's subjects can expect.

Such a link between public toilets and citizenship has a long history. The rights of citizenship to include access to appropriate public toilets emerged in the West with the rise of modernity. In this period, the design of the built environment (especially the urban) and the provision of services were increasingly shaped by concerns over public sanitation and by shifting definitions of private and public. Consequently, since the mid 19th century, the provision of public toilets has become an accepted demand on the state, as it has been acknowledged that citizens in public space need private places where they can relieve their bladder and bowel. Throughout the modern period, this provision has slowly been changing, progressing through a number of stages. Prior to the period of Enlightenment in Europe, urinating and defecating was a public act, taking place in fields and gardens, but also in the street. By the mid 19th century, however, it had become a private act, taking place in outhouses or inside the house, and was disciplined and socially regulated by Victorian reformers championing modern sewage systems and their promotion of discourses of public health (Law et al., 1999). At the same time and for the same reasons, public toilets were built using the public purse to provide citizens the means to urinate or defecate in public whilst away from the home. Privacy within these toilets was ensured by design guidelines and building codes, so that this public space was frequently divided by screens, demarcated by internal doors and shielded from the gaze of others by disrupted sight lines.

Throughout the modern period, however, where public toilets are sited, how they are designed and for whom they are intended have been contested. For example, the evidence at hand for Canada, New Zealand, Australia and the UK shows that provision of public toilets for women was late, partial and often gained through local and national civil rights campaigns (Andrews, 1990; Greed, 1996; Austin, 1999). More recently, other groups such as homeless people have sought to gain access to public toilet facilities (Law et al., 1999), whilst others have tried to 'escape' from their usage. In the latter case, parents and care-givers are campaigning for specific gender-neutral spaces in which to change a nappy and care for a baby, and are also promoting the acceptance of breastfeeding in public spaces such as parks and restaurants rather than in toilets. Similarly, gay activists have argued for the right for more safe spaces where gay men can meet other men for sex, away from public toilets that have long served as meeting-places (Chauncey, 1994; Nilsson, 1998). Disabled people then are part of a larger struggle to 
redefine citizenship in relation to public toilet provision, with their struggle defined around two distinct and somewhat separate issues related to citizenship: access and dignity.

Clearly, access is not just about spatial configuration and design, but is a political and social issue: it is about the ability to take part in public life. There is no denying that many disabled people are denied the same rights in comparison to more abled-bodied citizens in their ability to access and use public space. The disabled movement and their allies argue that the denial of access rights is an expression of a particular form of discrimination, ableism. They define ableism as the systematic discrimination of disabled people by non-disabled people through individual, institutional and social/cultural means (Kitchin, 2000). Ableism, the disability movement contends, leads to social injustices in the ways in which disabled people are treated and catered for by the state and other citizens. Using Iris Marion Young's (1990) examination of social justice, ableism, as with other forms of oppression such as racism, can be divided into five general types.

(1) Disabled people are rendered 'powerless': disabled people are kept in the same social position through political means and are being denied access to important decision-making positions within society. Disabled people are generally underrepresented in political positions at all levels (local, regional, national and international) and therefore lack a platform to give their views.

(2) Disabled people are marginalised within society and social life: disabled people are kept in the same social position through social means. Disabled people are generally 'pushed' into poor housing, denied access to private and public transport, and find it difficult to take part in 'mainstream' social activities such as visiting the pub or cinema through poor provision and weak statutory laws.

(3) Disabled people are exploited within the labour market: disabled people are kept in the same social position through material means. Disabled people are often excluded from the labour market through discriminatory practices and poor levels of mobility. Where they do gain access, it is usually in marginal positions undertaking low-paid, low-skilled work often on a part-time basis. Such a situation works to deny disabled people prosperity and wealth, and their associated power.

(4) Some disabled people are suppressed through violent means: disabled people are controlled through physical violence and imprisonment. For example, the system of placing some disabled people against their wishes in asylums has been one particular method used to confine and oppress disabled people.

(5) Disabled people are stigmatised through the use of cultural representations and myths: non-disabled cultural practices, lifestyles and images are promoted as the norm and, in general, disabled people are portrayed as abnormal and 'freaks of nature' thus legitimating how nondisabled people view and treat disabled people.

The denial of access rights contributes significantly to the reproduction of Young's points 2 and 3. Here it is recognised that the provision of accessible public toilets provides the minimum conditions under which disabled people can participate in social and political life. Without accessible toilets, people are subject to 'the bladder's leash' (Cooper et al., 1998), restricting how long they are able to stay in a place and thus constraining their participation. At present, for a large proportion of disabled people in the developed world-those with impaired mobility, especially those who use a wheelchair-most public toilets encountered are not accessible. Here, we refer to both public toilets intended for use by the general public (i.e. purpose-built public services paid for by the public purse) and those that are intended for use by customers and clients (i.e. toilets in areas populated by the public, but which are generally restricted to those 
paying for a service, such as a meal, and as such are not available to those just walking in off the street).

Moreover, the cultural meanings attached to relieving bladder and bowel mean that toilet provision involves more than access; appropriate provision means that toilet users must be able to exercise that access and use the service with dignity. The key element of this is privacy. Unlike ramps and buses, public toilets must be able to be used in private and in a way that minimises the potential for embarrassment. Going to the toilet is not a simple matter of performing a necessary bodily function; it is also an act which is connected to a range of cultural concerns and taboos about dirt, infection and bodily exposure (Douglas, 1966; Stallybrass and White, 1986). The dominant Western norms of proper toilet behaviour for adults include discreetly dealing with your body's needs, away from the gaze of others, in demarcated settings with some spatial separation from other activity spaces, using facilities which meet public health standards on the disposal of human waste and control of dirt. Consequently, to be placed in a situation where you are unable to relieve yourself without breaking the social conventions which surround the act can be understood as a denial of your rights to participate in social life with dignity.

We would suggest that the paucity of accessible public toilets reflects the longstanding exclusion of disabled people from public space and the public sphere. For much of the modern period, disabled people have been regarded as appropriately confined to the private spaces of the home and various kinds of institution. This separation and segregation has been reproduced by planners through a tradition of providing 'specialised spaces' for groups such as disabled and older people, such as sheltered accommodation and retirement homes (Imrie, 1996). As a consequence, disabled people have not been highly visible in public space, thus placing little pressure on service providers to cater for their impairments through better access provision. In a sense, there has been a per- ceived notion that there is little need to provide public toilets which are accessible because disabled people are not the occupants of public space. For example, the number of mainstream Irish schools with accessible toilets is presently extremely low (27 per cent in first-level schools), as it was never expected that they would be used by disabled children (Kitchin and Mulcahy, 1999).

The non-recognition of disabled people in public space has also been shared by those making decisions about the built environment. Architects, planners and builders until very recently have been under no obligation to provide accessible toilets in public spaces and buildings, and consequently few were ever installed. The issue of cost is often raised as an explanation, but is clearly not a sufficient explanation alone. The fact that these groups did not take it upon themselves to introduce accessible environments, Imrie contends, is the result of a neo-liberal climate and the fact that the ideas and ideals that underpin planning and architecture are form, aesthetics and mobility, not function and access (Imrie, 1996, see especially ch. 6).

Whilst these ideas and ideals remain, the legislative framework within most Western countries has however changed in recent years, with legislation concerning disabled access to public spaces introduced. This legislation though is highly variable across nation-states. For example, Gleeson (1999, p. 181) makes a distinction between the rights-based approach adopted in some states and the regulatory approach adopted in others. In the US, the rights-based approach is expressed in the American with Disabilities Act (ADA) which was submitted to Congress in 1988 and eventually signed into law in 1990. It required that all public accommodations (in other words, all privately owned buildings open to the public) had to be accessible to all people with any type of disability. In the UK, access to the built environment and to public space is legislated through the Town and Country Planning Act 1970, Disabled Persons Act 1981, Part M of the Building Regulations 1987, 1992, 1999 
and the Disability Discrimination Act 1996 (Imrie, 1996). Access is essentially governed by building controls administered by local councils. Other countries share elements of both approaches. For example, New Zealand is characterised by Gleeson as having a dualistic access framework. This includes the amended Building Act 1991 which requires that "a disabled person must be able to carry out normal activities and processes in that building" (Gleeson, 1999, p. 179).

The effectiveness of legislation to require accessibility is of course highly dependent on enforcement, and on the presence of ambiguities and loopholes. In the UK, Imrie (1996) shows how laws are poorly enforced by local authorities. For example, he reports that one local authority noted that they use the building regulations sparingly:

We use it about a third of the time, but, of this, less than 25 per cent of the applicants will actually conform to what we want (Imrie, 1996, p. 135).

The other 75 per cent were not prosecuted. In other cases, authorities found it very difficult to enforce the regulations, with developers choosing to ignore threats of action which rarely materialised, and 25 per cent of authorities admitted that they had taken little or no effort to enforce Part M. Thus, whilst change is sought, there is much resistance on the ground by both developers and authorities. $^{2}$

Indeed, many architects, developers and builders, who usually operate on principles of libertarianism, have resisted such changes on the grounds of increased costs and loss of floorspace. Others still object to wide-scale and costly changes which will not result in economic benefits to the provider group. Thus, we are currently witnessing a complex interplay between government institutions, legislative bodies, disability groups, the building trade and building owners, that is shaping accessible toilet provision in public spaces. ${ }^{3}$ Indeed, whilst the rights of disabled people may well be recognised by government, their lack of legislative enforcement in countries such as the UK and Ireland means that the socio-spatial landscape is largely determined by those resistant to access provision. This is leading, we would contend, to a reproduction of social injustices (as defined by Young) and the perpetuation of the marginalisation of disabled people.

\section{The Study}

In the rest of this paper, we examine the experiences of disabled people attempting to participate in social life and use public space in Ireland. Our central questions are: to what extent do disabled people have access to places to relieve themselves in dignity, and, how does the provision (or lack of provision) of accessible toilets affect participation in public life? To explore these questions, we provide an analysis of interviews with 35 disabled people and a case study of provision in one town, Newbridge, located in County Kildare, Ireland. The interviews formed part of a larger study concerning how research on disability issues should be conducted. ${ }^{4}$ Part of the interview concerned what issues needed to be researched further. Many of the respondents suggested access, and many went on to detail specific examples and how they affected their daily living; the analysis presented here draws from this aspect of the interviews. The 35 disabled people interviewed had a variety of physical, sensory and mental impairments, and the transcripts below are mainly drawn from wheelchair users, although access to toilets was mentioned by 50 per cent of all respondents. Of the interviewees, 16 either lived in the Belfast Urban Area or within 15 miles of Belfast city centre and the other 19 either in Dublin or County Kildare. Interviewees in Belfast were sampled using a snowballing method, with initial contacts supplied by Disability Action. ${ }^{5}$ Interviewees in Dublin were arranged by the Irish Wheelchair Association, and in County Kildare using a snowball sample.

The interviews were conducted between March and November 1998 by the first author. Interviews lasted from 25 minutes to over 3 hours. Of the respondents, 24 were interviewed separately, either in their home 
or place of work; 2 were interviewed as a pair; and the remaining 9 in 2 focus groups of 6 and 3 (these were training centre and day centre attendees). Interviews were taped except in one case where notes were made by both interviewer and interviewee. All the interview data were transcribed, typed into plain ASCII files and imported and analysed using NUD-IST 4.0 (Non-numerical Unstructured Data Indexing Searching and Theorising). To allow the data to 'speak for themselves', we have used original passages from the interviews, but all respondent names have been changed to preserve anonymity.

The case study comprised an access audit of Newbridge, a reasonably large regional town (population 13 363; OCPS, 1996) located in County Kildare (population 134 992) in the Republic of Ireland. ${ }^{6}$ The availability of accessible toilets in the town was assessed as a component of a larger study which mapped in detail access to the built environment in general. ${ }^{7}$ This project is on-going and is a collaborative project, undertaken through a partnership between the local access group and the local university, and is action-orientated. ${ }^{8}$ Indeed, one of the central aspects of the project is to use the maps produced to lobby the local council and businesses in Newbridge to tackle existing problems, including the provision of accessible toilets, and to adopt more disabledfriendly planning approaches in the future.

\section{An Analysis of the Socio-spatial Con- struction of (In)accessible Public Toilets}

Our analysis revealed four main themes in relation to public toilet provision, each illustrating the partial nature of citizenship experienced by disabled people in Ireland.

First, respondents expressed concern over the lack of accessible public toilets. All the interviewees described how most towns in Ireland (North and South) seem to have no, or very little, accessible toilet facilities. In the cases where there was provision, these toilets are often hidden (unannounced) in particular shops, cafes and pubs, which pro- vided toilet facilities for customers and not everybody who wandered in off the street. Here, prior knowledge of the existence of the toilet is needed and, technically, some custom to the facility's owner given. Thus, it was evident that disabled people are clearly being denied levels of provision available to other citizens and are being excluded from public spaces. For example, Yvonne who worked in a shopping centre in Belfast stated:

There are no disabled toilets in this centre simply because the disabled toilet used to be regularly vandalised. And that's the reason they shut it.

As a consequence, despite working from 9 until 5 o'clock in the centre, Yvonne had to travel to another centre nearby to use the toilet facilities, an undertaking that no other employee was expected to take. Similarly, Aine, who was born and raised in Longford (population 6444; OCPS, 1996) and still visits regularly to see her parents, cannot socialise for long periods in any of the town's pubs, restaurants and hotels, because she has to return home to use the toilet.

Aine: There is no toilet in Longford in a hotel, or restaurant or pub. No disabled. Only one, the one in the shopping centre.

For those disabled people living in the town, the only accessible public toilet is in the new shopping centre, a facility that is intended for use by shopping centre patrons only.

This poor provision described by the interviewees was borne out in an access audit of Newbridge. Up until 1999, there were no accessible public toilets funded by the public purse in Newbridge, despite its size and regional context. Moreover, until recently, no other public space such as shops, cafes, pubs, hotels, cinemas, health centres, sports centres, libraries, etc. had accessible toilets for customers, clients and indeed workers. This can be placed in context by the fact that until 1998 none of Newbridge's 40 pubs had an accessible toilet. ${ }^{9}$ In the past three years, the number of accessible toilets in the town has increased. The access audit of the town re- 
vealed that there are now a number of accessible toilets, only one of which is clearly visible, with the other locations being determined by word of mouth. Indeed, whilst undertaking the audit, it became clear that members of the local access group did not previously know of the existence of a number of the toilets.

So far, 12 accessible toilets have been located in the town (a number that surprised the access group), 7 of which have been installed in the past 18 months: 1 in a bank, 1 in a parish centre, 1 in a sports centre, 1 in a new credit union, 2 in new cafes, 2 in refurbished pubs, a new public toilet on the main street (opened October 1999), 1 in a new health centre, and 2 in new hotels. In 2 cases, permission/key to use the toilet has to be sought, and in 1 case the toilet cannot be used as it is currently a storeroom. None of the toilets is a model accessible toilet, each having a number of faults (such as one side transference only, no large handle taps, etc.), although most are adequate. The local access group are concerned over the design of the new purpose-built accessible toilet, which is located on a slope and whose surrounding street area seems badly designed, with the nearest designated parking space over 200 yards away. For those visiting the town, only the 1 toilet is apparent, that on the high street. At least 2 of the toilets are only in existence due to pressure from the local access group, and the installation of a number of the others has no doubt been influenced by this group which has been very proactive in seeking changes in access provision in general. As far as we are aware, none of the toilets is the result of state-defined citizenship and enforced through legislation.

From discussions with the local access group and the Kildare Network of the Irish Council for People with Disabilities, an umbrella group for the county as a whole, it is clear that, whilst the situation in Newbridge is bad, it is however exceptional in relation to the county as a whole, both in the level of provision and the success of its access group, which is by far the most active in the county. The number of accessible toilets in the rest of the county is very limited, and a number of towns with populations greater than 1500 have no accessible toilet. For example, Kilcock with a population of 1825 (OCPS, 1996), a small town that serves a large farming community, has a number of shops and 5 pubs, but no accessible toilet. In some senses, then, the disabled people of Newbridge are better off than others living elsewhere in the county, a fact that reveals the extent of disabled people's exclusion from public space in Ireland.

This limited provision of toilet facilities, especially in the Republic of Ireland context, is unsurprising given the limited and ineffective legislation that is supposedly meant to increase and safeguard disabled people's access rights. In the Republic, the only pieces of legislation related to accessibility are the 1990 Building Control Act and Part M of the Building Regulations 1991 and 1997. Under Part M, five requirements are made (NRB, 1998):

M1 Reasonable provision shall be made to enable disabled people to have safe and independent access to a building and to those parts of a building to which it is appropriate to have access.

M2 If sanitary conveniences are provided in a building, reasonable provision shall be made for disabled people.

M3 If a building contains fixed seating for audience or spectators, reasonable provision shall be made for disabled people.

M4 In this Part 'disabled people' means people who have an impairment of hearing or sight, or an impairment which limits their ability to walk or which restricts them to using a wheelchair.

M5 This Part does not apply to dwellings (although Technical Guidance Document to Part M, paragraph 0.2 states that "it does apply to the common areas of apartment blocks and the like").

As outlined above in relation to the UK, this legislation is quite weak and is very poorly enforced; indeed, we know of no prosecutions under the terms of this part of the 
Regulations. This weakness has recently been acknowledged by the Irish government which has published a consultation document acknowledging the failure of the legislation and condemning those that have used the 'reasonable provision' clause to make minimum access provision (Department of Environment and Local Government, 1999). In short, the legislation has had a minimal effect on disabled access in Ireland, invoking slow and ad hoc change in the landscape.

A consequence of this weak legislation and poor enforcement is, at the time of writing, accessible public toilets in Ireland (both North and South) are, as our respondents indicated, few and far between. Most of those that exist have been built in the past 10 years and are sited in new buildings. Thus, accessible toilets are still relatively rare, particularly outside the main conurbations. For example, disabled people interviewed in the Kitchin et al. (1998) study claimed that there were only 3 accessible public toilets, all in shops, in County Donegal, a large rural county in the north-west of Ireland (population 129 994; OCPS, 1996). While this is likely to be an underestimation, there is little doubt that accessible toilets in this county are very few and far between, especially when compared to those available to non-disabled people.

A second main theme concerned the poor design of those toilets that had been installed. Toilets failed to meet standards in one of two ways, either being unreachable or unusable. In the initial instant, the toilets themselves were fine but they could not be used as the disabled people could not access them. The most common problem was that entry to the toilets was prevented by steps, either into the premises, or inside the premises. For example,

Shane: Like Harry Africa [a restaurant] across the road. They put up a sign saying "disabled toilet". But they neglect to say that there is a two-foot step to get in to the place. They try to do a bit but they never quite get it right.

Luke: some McDonald's have a wheel- chair toilet but they have steps into it as well. As far as they are concerned they have a wheelchair toilet, but it's no use if you can't get into it, like on Grafton Street where there is three steps up to the place.

This lack of thought in thinking through toilet provision in relation to access in the rest of the building is highly frustrating to disabled people, especially when accessible toilets are relatively rare. In the second instance, the design of the toilets themselves is inadequate. For example, Ciara stated that:

Ciara: Now with the new regulations every new building is meant to have a wheelchair accessible toilet. Well they have one but not all of them are very well designed. Some of them you can't close the door. Because you have to remember that everyone has different-sized wheelchairs. I mean this wheelchair is massive. And it just won't get in half the time. I've also been to some places where there are wheelchair accessible toilets available but they are up stairs!

\section{Similar concerns were expressed by Fiona:}

Fiona: I found recently in a hotel-a friend, a colleague of mine, her sister got married out in Jamaica but she had one of those evening services-Nuala who works alongside us had to go to the toilet later on that evening. And I said to the staff-and she had rung up the hotel, just outside Derry, and they had taken it because they said it was accessible-and we asked where was the toilet and she said "it was way down through". And she took me, gave me keys, opening doors, going down all these corridors and all these doors were opening and everything else and she made a great big show of this accessible toilet, and Nuala could have got in but the world and his wife could have seen her going to the loo, you know-we couldn't get the door closed. So I says to her "your toilet's not very accessible she can't use it", and she says, "everybody tells us that!" And I thought "well why don't you widen the door or shift the door around". So even if 
you get the transport it might not be accessible or you'll find beer kegs because it's being used as storage-I mean they get it and they may even get a grant for it and they don't use it or they get it wrong because you have to think about ... Nuala wasn't on what you call a manual, she was on electric wheelchair-and they are bigger and bulkier.

Here an effort has been made to provide an accessible toilet, but little thought has actually been given to what this means in practice and it serves little more than a cosmetic exercise. Such instances are particularly frustrating on an number of counts. For example, as Fiona describes, disabled people often phone ahead to make sure that the venue is accessible, including an accessible toilet, and attend on the basis that there is provision. However, it is only on reaching the venue and going to the toilet to use it that they discover that it is in fact inaccessible. This generally leads to an embarrassing and undignified situation of having to try and use the toilet in any case, or to go home (an option not always available). Moreover, in many cases, the management of the venue already know about the problems of the current design, but do little to address it or to tell disabled customers ahead of their attendance. Further, it needs to be remembered that disabled people with different impairments use the toilet differently. For example, some people transfer from the left, others from the right, some face forwards, others backwards. Thus, toilets designed for use by disabled people are planned around a very narrow view of how they will be used.

The third main theme centred on the misuse of disabled toilets. It is quite clear from the interview material and anecdotal evidence that disabled toilets are often used in ways that they are not intended for. For example, in the following passage, two interviewees discuss this issue and the fact that disabled toilets seem to be a separate concern from other public toilet provision.

Shane: Or you find that toilets are being used as a store cupboard.
Laura: Or the door is locked. But the very fact that it is called a "disabled toilet"-I just getting weary of it all.

Shane: It should just be one word-toilet. After all you don't go into one and see blacks only or whites only. So why should disabled people have a label put on them?

Indeed, disabled toilet provision is seen largely as a separate concern, and is after all legislated for separately. This separate provision reveals the ideological bias towards separating and segregating disabled people in public space. If disabled people were equally valued members of society, then all toilets would be accessible and their provision would not be an issue and would not need to be legislated. Clearly, however, the secondclass citizenship bestowed on disabled people is accepted unproblematically by most of the general population.

The fourth main issue is one that has been implicitly discussed so far, that is the fact that disabled toilet provision delimits the spatial behaviour of disabled people. In other words, disabled people often plan their daily spatial routines around the provision of toilets, avoiding locations where there is no provision, and consequently having a constrained, daily home range and constrained patterns of spatial behaviour. As Aine details, this concerns nearly every aspect of daily life:

Aine: Because when, as I say, you go outside your door if you're going someplace-if you're going to a shopping centre, going to a pub, going to a hotel; if you are going to a cinema, or any type of entertainment, or if you're going to a class in a school or college, you have to check to see if there is a toilet there. Otherwise, you can't spend longer than three hours away from the house.

Similarly, Luke limits his socialising to a handful of pubs where there are accessible toilets:

Luke: Getting in is okay, but toilets would be the problem. Most places I go to I do 
make sure there is an accessible toilet. I'd usually just drink in those places.

As a consequence, the places disabled people shop, work and socialise in are to a degree planned around access to toilets, especially if the trip will be longer than a couple of hours. Certainly, Aine rang ahead to every venue she visited to ask if there was provision, and did not go unless there was an accessible toilet. This severely limited her patterns of spatial behaviour to one shopping centre outside her town of residence (she could not shop on the main street as most of the shops were inaccessible), one pub and one cinema (located further away than her local cinema). Other interviewees adopted this phone-ahead strategy, and many had built up a comprehensive knowledge of where toilets were in their local area and along main routes across the country. Because disabled people take it on themselves to monitor and restrict their behaviour in light of the restricted facilities, the outcome is that their constrained mobility becomes naturalised and invisible to others. To some extent, this replicates the constrained mobility experienced by women facing environments that are unsafe after dark: because the constraint is the immediate result of self-limiting behaviour, the wider structural reasons for the constraints are not always recognised and remain in place. As a consequence, attitudes to public toilet provision are reproduced and the status quo perpetuated.

Similarly, we found that disabled people living in, working in or visiting Newbridge, have limited access to facilities in the town and often have to be prepared to travel between premises to find toilets even though they are available to other customers in situ. This means that activities have become limited to locations with accessible facilities. For example, Newbridge Access Group and the Kildare Network and who meet regularly in the town, have to limit their meetings to either the parish centre or one of the two hotels with accessible toilets. Going for a social drink after the meeting is limited to the one of the two pubs with an accessible toilet.
Choice afforded to other people is clearly constrained in these cases, and it is clear that disabled people in Newbridge have partial levels of citizenship, with their right to be in public space questionable.

\section{Conclusion}

In this paper, we have argued that analyses of access to the built environment need to be framed within a framework centred on citizenship and rights-based conceptions of social justice. This approach has two benefits. First, it provides a theoretical position in which to understand how public toilet provision is shaped by individual and institutional socio-spatial processes. Secondly, it frames access issues within a civil rights framework and provides a useful political strategy to engage policy-makers. Here, the approach is used to argue for a revisioning of citizenship and the creation of a more inclusive society in which every citizen, regardless of impairment, has the right to access public space in dignity. In this sense, then, the arguments for access which have been mounted in support of accessible buildings and transport services can be mobilised for public toilets. Here, there is a recognition that the rights of disabled people do not rest on their contribution (financial or otherwise) to society but on a wider basis of egalitarian and utilitarian ideals. This means reconfiguring traditional, distributive models of social justice in which disabled people are envisaged as recipients of social welfare not as citizens with full rights (Young, 1990; Gleeson, 1999). Such systems, it is suggested, are sustained by the false perception that disabled people are/were 'takers' and not 'givers' to the social system and society. This approach is already being implicitly and explicitly adopted by the disabled movement to support their claims for more appropriate provision of facilities but, so far, at least in the case of Ireland and the UK, with only limited success.

Using this approach, we have demonstrated that disabled people in Ireland and the UK have differing levels of access to public 
toilets from non-disabled people; that toilets are often inappropriately designed, restricting dignified use; that toilets are often inappropriately used; and that these three issues combined have far-reaching consequences for disabled people, limiting their use of public space and constraining them to particular patterns of spatial behaviour. This situation is being reproduced through weak legislation which only partially acknowledges disabled people's moral rights to access public space. Thus, despite the rhetoric of civil rights for all and recent pieces of legislation aimed at improving access in general, disabled people are still being conceived of as essentially second-class citizens. In order to challenge this social injustice, attention needs to be directed at redefining notions of citizenship, changing attitudes of design professionals and the general public, strengthening and enforcing access legislation, and investing in infrastructure. We hope that this paper will help to contribute towards these ventures.

\section{Notes}

1. Imrie (2000) describes three main approaches: behaviouralism (see, for example, Golledge, 1993); socio-political (see, for example, Gleeson 1996, 1999; Imrie, 1996); and sociobiological (see, for example, Butler and Bowlby, 1997).

2. Buildings and public spaces are not the whole story, however, and it is also important to think about access to toilets in other contexts. For example, toilets are needed and provided on most forms of long-distance public transport (for example, coach, train and aeroplane). At present, however, they are only available in any numbers on trains, and are then usually restricted to one coach per train. On coaches and aeroplanes, provision is severely limited and discussions with several disabled people reveal that the general attitude from operators seems to be 'cross your legs and hope for the best'!

3. Pfeiffer (1996) provides a useful history of such interplay in discussing the 'New York City toilet flap' of 1992 which took place soon after the Americans with Disabilities Act was passed.

4. 'Developing a participatory action research programme: access, accessibility and measur- ing disabling environments', funded by the Royal Irish Academy.

5. Disability Action is a Northern-Ireland-wide organisation that provides advice and support to disabled people and campaigns on disability issues.

6. Although it should be noted that Newbridge grew substantially in the late 1990s, when it was redeveloped as a satellite town for Dublin.

7. See http://www.may.ie/staff/rkitchin/newbridge.htm, for full details of the project, access maps and photographs.

8. Action-orientated research aims to use the results from the research project to change the social, political and economic conditions of people within the area studied.

9. Newbridge has a large number of pubs for its population size due the nearby presence of the Curragh Army base.

\section{References}

ANDREws, M. (1990) Sanitary conveniences and the retreat of the frontier: Vancouver, 18861926, BC Studies, 87, pp. 3-22.

Austin, K. (1999) Convenience stories, The Sydney Morning Herald, 24 April, p. 7s.

Butler, R. and Bowlby, S. (1997) Bodies and spaces: an exploration of disabled people's experiences of public space, Environment and Planning D, 15, pp. 411-433.

Chauncey, G. (1994) Gay New York: Gender, Urban Culture, and the Making of the Gay Male World, 1890-1940. New York: Basic Books.

CoOper A., Law, R., Malthus, J. and Wood, P. (1998) Rooms of their own: public toilets and gendered citizens in a New Zealand city, 18501950. Unpublished paper, available from Cooper, Department of Gender and Women's Studies, University of Otago.

DEPARTMENT OF THE ENVIRONMENT AND LOCAL GOVERNMENT (1999) Consultation Document. Revision of Part M: Building Regulations. Dublin.

Douglas, M. (1966) Purity and Danger: An Analysis of Concepts of Pollution and Taboo. London: Routledge.

FinKelstein, V. (1993) The commonality of disability, in: J. Swain, V. Finkelstein, S. French and M. Oliver (Ed.) Disabling BarriersEnabling Environments, pp. 9-16. London: Sage.

GLEESON, B. J. (1996) A geography for disabled people?, Transactions of the Institute of British Geographers, 21, pp. 387-396.

GLEeson, B. J. (1999) Geographies of Disability. London: Routledge.

Golledge, R. G. (1993) Geography and the dis- 
abled: a survey with special reference to vision impaired and blind populations, Transactions of the Institute of British Geographers, 18, pp. 63-85.

GreED, C. H. (1996) Planning for women and other dis-enabled groups, with reference to the provision of public toilets in Britain, Environment and Planning A, 28, pp. 573-588.

IMrIE, R. (1996) Disability and the City: International Perspectives. London: Paul Chapman Publishing.

ImRIE, R. (2000) Disability, in: R. Johnston, D. Gregory, G. Pratt and M. Watts (Eds) Dictionary of Human Geography, pp. 178-180. London: Blackwell.

Kitchin, R. M. (1998) 'Out of place', 'knowing one's place': towards a spatialised theory of disability and social exclusion, Disability and Society, 13, pp. 343-356.

Kitchin, R. M. (2000) Disability, Space and Society. Sheffield: Geographical Association.

Kitchin, R. M. and MulcAhy, F. (1999) Disability, access to education, and future opportunities. Combat Poverty Report, Dublin.

Kitchin, R. M., Shirlow, P. and Shuttleworth,
I. (1998) On the margins: disabled people's access to and experiences of employment in Donegal, West Ireland, Disability and Society, 13, pp. 785-806.

Law, R., Cooper, A., Malthus, J. and Wood, P. (1999) Bodies, sites, and citizens: the politics of public toilets. Unpublished paper.

NiLsson, A. (1998) Creating their own private and public: the male homosexual life space in a Nordic city during high modernity, Journal of Homosexuality, 35(3/4), pp. 81-116.

NRB (1998) Buildings for Everyone: Access and Use for all the Citizens. Dublin: NRB.

OCPS (OFFICE OF CENSUS AND POPUlation SuRveys) (1996) Small Area Population Statistics. Dublin: OCPS.

PFEIFFER, D. (1996) 'We won't go back': the ADA on the grass roots level, Disability and Society, 11, pp. 271-284.

Stallybrass, P. and White A. (1986) The Politics and Poetics of Transgression. London: Methuen.

Young, I. M. (1990) Justice and the Politics of Difference. Princeton, NJ: Princeton University Press. 
Copyright of Urban Studies is the property of Carfax Publishing Company and its content may not be copied or emailed to multiple sites or posted to a listserv without the copyright holder's express written permission. However, users may print, download, or email articles for individual use. 